\title{
Multi-Infarct Dementia: A Historical Perspective
}

\author{
Erin McKay ${ }^{a}$ Scott E. Counts ${ }^{a-d}$ \\ a Department of Translational Science and Molecular Medicine, Michigan State University, \\ Grand Rapids, MI, USA; ${ }^{b}$ Department of Family Medicine, Michigan State University, \\ Grand Rapids, MI, USA; ' Hauenstein Neurosciences Center, Mercy Health Saint Mary's Hospital, \\ Grand Rapids, MI, USA; dMichigan Alzheimer's Disease Core Center, Ann Arbor, MI, USA
}

\section{Keywords}

Vascular dementia · Cerebrovascular disorders · Cerebral infarction · Leukoencephalopathy

\begin{abstract}
Background: Multi-infarct dementia (MID), a prominent subtype of vascular dementia (VaD), has only achieved recognition in the last 4 decades. Since its original description, the characterization, etiological understanding, and therapeutic direction of MID and other VaD subtypes has progressed at an astounding rate. Summary: This paper divides the landmark discoveries and emergence of new research strategies for MID into decade-defining patterns so that a condensed picture of the total history of MID and its eventual inclusion as a VaD subtype emerges. This paper follows the first descriptive decade, a shift to a preventative focus, a renewed interest coinciding with timely advances in research technology, and a hopeful return to treatment possibilities for $\mathrm{VaD}$. Key Message: Concisely tracing the historical lineage of the modern understanding of MID, both as a singular entity and as part of the VaD constellation of disorders, provides a novel perspective on the foundation upon which future advances in combating vascular contributions to dementia will be based.
\end{abstract}

(C) 2017 The Author(s)

Published by S. Karger AG, Basel

\section{Introduction}

Multi-infarct dementia (MID) is considered the most common form of vascular dementia (VaD), a primary cause of dementia second to Alzheimer's disease (AD) [1]. MID is defined as cognitive impairment resulting from multiple lesions and infarcts in both white and gray matter that follow occlusions in cerebral arteries and arterioles [2]. MID was used as a nearly 
interchangeable term with VaD before the recognition of dementia subtypes resulting from single infarcts or genetic arteriopathy [3]. Vascular pathology has been found to be the root cause of dementia in about $8-10 \%$ of all clinical cases of cognitive impairment, and $25-80 \%$ of AD patients display vascular lesions that may contribute to their dementia [4]. MID and other VaD subtype symptomology variably includes prominent impairment in executive functions involving attention, working memory and perceptual speed, mild episodic memory deficits, affective disturbances, and gait abnormalities, which progressively interfere with daily life activity of the patient and increase the emotional and economic burden for caregivers [5]. VaD was also estimated to have the highest annual cost per patient among the most common dementias, likely due to a higher rate of recurrent hospital admissions [6]. However, no approved treatment currently exists to modify cognitive decline once it has become apparent [7]. As such, prevention of strokes and management of risk factors are the only universally and medically accepted means of controlling the onset of MID [7].

While the incidence of $\mathrm{VaD}$ is variable across studies, several meta-analyses have concluded that nonhereditary VaD typically occurs around the age of 65 years and then increases exponentially every 5 years afterwards [8]. Moreover, with an aging population and better health care available, the rates of all dementias are expected to nearly double every 20 years [9]. The risk factors for stroke are also gaining prevalence, with more people being classified as hypertensive or prehypertensive rather than normotensive, and with more than half of these cases not adequately controlled [10]. Hence, the lack of valid treatment, the high likelihood of increased incidence, and the greater prevalence of risk factors for VaD justify an increased interest in understanding and treating this debilitating neurologic disorder.

While many recent reviews have covered our current knowledge of this disorder in depth $[2,4,11]$, few have traced the major contributions to this knowledge base from a historical perspective. This review will follow the major experimental and theoretical milestones in MID research to date.

\section{The 1960s and 1970s: Discovery and Differentiation}

\section{Early Understanding of Vascular Pathology and Dementia}

Vascular contributions to AD were noted in the early 1900s with amyloid plaques observed in the arteries and capillaries of patients who died with dementia [12]. Alois Alzheimer even described lipid plaques (i.e., atheromatosis) in the vessels of patients who had been diagnosed with senile dementia [13] and noted small vessel arteriosclerosis in his most historically significant patient, Auguste Deter [14]. New histological tools such as silver stains allowed him to recharacterize the disease with the signature neurofibrillary tangles and senile plaques recognized to this day $[13,14]$. Hence, the notion of vascular contributions to dementia was recognized even before the hallmark lesions that have become universally linked to a variety of dementias.

However, it was not until the late 1960s and early 1970s that the concept emerged that vascular abnormalities could lead to a dementia phenotype in the absence of a comorbid primary degenerative dementia diagnosis. Primary dementia was defined at the time as any progressive dementia resulting from the degeneration of the parenchymal tissue of the brain without the presence of vascular pathology [15]. During this time there also began a clear dissociation from the original arteriosclerotic theory of dementia, where narrowing of the arteries was thought to result in global ischemia and dementia [15]. This was supported by clinicopathological studies which found comparable levels of arteriosclerosis in brain samples of patients who had died with dementia and in those of patients who had died without dementia $[16,17]$. This led to the concise conclusion by the clinical neurologist C.M. Fisher 
that $\mathrm{VaD}$ developed not from an overall decrease in blood flow due to arteriosclerosis, but from a cumulative effect of large and small strokes [18]. According to this new understanding of $\mathrm{VaD}$, arteriosclerosis and hypertension are contributing risk factors for, but not causative agents of, the focal ischemia underlying cognitive impairment [19]. Rather, embolisms from both extracerebral and intracerebral origins and intracerebral thrombi would lead to focal ischemia and infarcts [19]. From this work, Hachinski, Lassen, and Marshall noted that in most cases where dementia could be linked to cerebrovascular disease, it resulted from multiple infarcts rather than an atherosclerotic strangulation of the brain, thus introducing the concept of MID to replace arteriosclerotic dementia [15]. At this time, the idea of strategic infarcts leading to dementia following just a single stroke had not yet been suggested. Therefore, MID was treated as synonymous with cerebrovascular dementia [15].

\section{Early Attempts at Clinical Differentiation}

In tandem with this mechanistic differentiation of MID from AD-type dementias, accepted differences in clinical presentation of the disorders also emerged. It was established that both led to a substantial deterioration of intellectual function [20]. However, the diverse functions of the cerebral cortex and subcortical projection nuclei in cognition left the door open for more definitive classifications. Perez et al. [21] conducted one of the initial studies attempting to clinically delineate MID from AD by comparing scores on the Wechsler Adult Intelligence Test with postmortem diagnosis. They found evidence that AD patients scored worse than age-matched VaD patients, but they also observed a near-chance level of misdiagnosis (51\%) with MID patients [21]. Moreover, the number, size, and location of the infarcts all impacted the degree of cognitive deficits in the MID patients [21], thus providing some of the earliest evidence for the heterogeneity of $\mathrm{VaD}$.

C.M. Fisher [18] distinguished cerebrovascular dementia patients not by the degree of the deficits, but by specific areas of impairment. Among these symptoms are intellectual deterioration accompanied by motor deficits such as irregular and slow gait, dysarthria, and dysphagia. Birkett [22] examined psychiatric disturbances in an institutionalized sample of dementia patients but could find no difference in psychiatric features between AD-type dementias and VaDs. Both Fisher and Birkett agreed that the deficits associated with AD appeared to have a more progressive, insidious onset than those of $\operatorname{VaD}[18,22]$.

\section{Initial Predicted Treatments for MID}

The emerging concept that the pathophysiology of MID resulted from several remote ischemic strokes led to new strategies for early intervention and treatment. At this time, VaD was considered to be the sole cause of dementia in only a minimal number of dementia cases $[23,24]$. However, vascular contributions to dementias, particularly AD-type dementias, were a focus of many clinical trials as the vascular contributions were considered more amenable to treatment and management than primary neuronal degeneration [25]. Early pharmacological interventions focused on vasodilators. It was believed that by increasing cerebral blood flow, neuronal metabolism would be improved and the health and functioning of neurons that survived ischemic events would be enhanced [26].

Anticoagulants were also a proposed therapy in the late 1960 s to prevent the formation of potentially dangerous thrombi [27]. This coincided with the discovery that discrete ischemic strokes from embolisms caused the multiple infarcts leading to cognitive and motor dysfunctions [19]. However, by the early 1970s it was noted that the risks outweighed the benefits in hypertensive, at-risk populations. Hemorrhage was a common complication in long-term anticoagulation treatment, and this risk increased with age [28]. Ultimately, these therapies did not affect survival or prevention of further strokes in clinical trials, and anticoagulants were discarded as a long-term treatment option by the end of the 1970s [29]. 


\section{The 1980s: Prevention and Reclassification}

\section{Management of Risk Factors}

Hypertension and atherosclerosis were already accepted as primary risk factors for MID [19]; yet, further research into the multifactorial etiology of the disorder was limited in comparison to research into poststroke treatment. In the wake of disappointments such as anticoagulant therapy [29], the focus shifted to the identification and management of risk factors for MID. Meyer et al. [30] examined the clinical profiles of 175 MID patients without comorbid AD compared to 125 cognitively normal controls. They found that hypertension was the dominant risk factor that separated the MID patients from the controls. However, heart disease, smoking, diabetes, and hyperlipidemia were also significant predictors [30]. This study also found a higher rate of MID among males over 60 years of age than among similarly aged females, suggesting a sex difference in risk [30].

When vascular risk factors were controlled in a clinical population of MID patients by the management of systolic blood pressure and cessation of cigarette smoking, patients displayed improved cognitive scores over a 2-year period [31]. Notably, the reduction of blood pressure had to be minimal in this elderly population, since chronic hypertension coupled with diminished autoregulation led to a requirement of some degree of high blood pressure to ensure healthy perfusion rates [31]. While these interventions often resulted in only mild improvements, they represented a departure from the general consensus at the end of the previous decade, which closed with tentative hope for prevention of further decline but no hope for reversal or recovery [32].

\section{White Matter Lesions}

Until the 1980s, MID was characterized by cortical infarcts or gray matter lesions, and the extent of the volume affected was thought to correlate with the extent of dementia [33]. This led to the theory that the death of cell bodies, particularly in the frontal cortex, accounted for the executive functional deficits that predominate in MID [34]. While MID was considered nearly synonymous with VaD until the 1980s, a new focus on white matter lesions led to an increase in the diagnosis of "Binswanger's disease" [35].

Otto Binswanger was the first to describe progressive leukoencephalopathy, though he included only minimal clinical details [36]. This disease was once considered incredibly rare, until the imaging techniques of the 1980s led to the discovery that white matter lesions were present in up to $16 \%$ of pathologically aging brains without comorbid AD [37]. It was not entirely clear at this time that white matter lesions could be caused by white matter infarcts as a variation of MID, though this was proposed as the so-called lacunar theory [35].

The manner in which the brain is vascularized makes it particularly vulnerable to hemodynamic changes. As large arteries from the exterior of the brain penetrate the periventricular white matter, the number of collaterals decreases, leading to a watershed area susceptible to ischemic attacks [35, 38]. De Reuck et al. [38] championed this theory by reporting that postmortem white matter damage was more pronounced than gray matter damage in $4 \mathrm{VaD}$ subjects. Furthermore, the U fibers were always uniquely spared among the white matter tracts affected, likely because their blood supply comes from a more proximal source than deep penetrating arteries [39]. Myelinated fibers were found to become demyelinated during periods of acidosis that occur under ischemic conditions [40]. This led to a significant reevaluation of the definition of MID in the 1980s, as De Reuck suggested that the incidence of VaD caused by white matter infarcts, once thought rare or nearly nonexistent, was actually the most common subtype of $\mathrm{VaD}[38]$. 


\section{Advances in Neuroimaging}

Neuroimaging by either computed tomography (CT) or magnetic resonance imaging (MRI) proved to be a great asset in revealing the contribution of white matter lesions to VaD and in separating VaD from AD premortem [41]. The use of CT to study VaD-specific changes actually began in the late 1970s with a focus on differences in ventricular size and low attenuation regions indicative of infarcts between individuals suspected to have VaD and those suspected to have another dementia $[42,43]$. The advent of using MRI to study VaD versus $\mathrm{AD}$ in the 1980s was a critical advancement for detecting differential tissue damage suggestive of one cause of dementia versus another [41,44]. T2-weighted MRI was found to provide the best-contrast image and was ultimately determined to be more sensitive than CT for detecting white matter lesions and infarcts [41]. Today MRI, both T2-weighted and fluid attenuated inversion recovery (FLAIR), are commonly used to study suspected VaD [45].

\section{The 1990s: Modern Methods Build New Avenues for Discovery}

\section{Genetic Contributions}

In 1995, the mapping of cerebral autosomal dominant arteriopathy with subcortical infarcts and leukoencephalopathy (CADASIL) to chromosome 19 in 7 French families opened the door to investigations into the genetic basis for VaD [46]. Joutel et al. [47] identified Notch3 as the critical protein encoded by the region on chromosome 19 implicated in CADASIL. Although CADASIL has been referred to as hereditary MID based on its recurrent subcortical stroke pathology [48], Chabriat et al. [46] also noted a few distinct differences between CADASIL and spontaneous VaD in their original characterization. Notable differences included the age at first clinical presentation, etiological contributions, and early symptomology. CADASIL tends to emerge earlier than MID, usually presenting at 45 years of age on average [46]. Moreover, infarcts occur in the absence of any age- or primary dementia-linked contribution to ischemic attacks, such as large vessel arteriosclerosis or amyloid angiopathy [46]. A final variance in CADASIL not found in nonhereditary VaD is the occurrence of migraine with aura, which becomes noticeable around a decade before dementia symptoms [46]. By contrast, the similarities between CADASIL and nonhereditary VaD include the predominant involvement of small vessels manifested as critical degeneration of the smooth muscle cells [48]. Furthermore, CADASIL and spontaneous VaD share a distinction from AD in that executive dysfunction is typically the first symptom to emerge, rather than episodic memory deficits [48].

\section{Animal Models}

In addition to the new focus on genetic factors underlying the susceptibility to dementia with vascular causes, 3 new animal models were introduced which opened the door to in vivo studies of MID: middle cerebral artery (MCA) occlusion, induced embolism, and spontaneous hypertensive stroke-prone rats (SHRSP) [49]. None of these models perfectly replicated the complexity of MID, but each had its own strengths and weaknesses.

MCA occlusion was initially proposed as a model of VaD in 1981 [50], but it did not gain prominence until the following decade. In this model, transient occlusion results in focal ischemia, leading initially to small lesions with gradual necrotic tissue damage [51]. The benefits of the MCA occlusion model include the relative reproducibility of the volume and location of infarcts [50], although the infarcts occur only in regions supplied by the MCA and are not specific to small vessels [51]. In addition, the cause of the stroke in this animal model is not the same as in MID, so the model lacks true construct validity [49]. 
Cerebral embolism can be induced in rats by injecting microspheres of carbon into the internal carotid artery [52]. This leads to progressive cerebral ischemia, metabolic disturbances, and cerebral infarcts [52]. This model has also been shown to induce memory deficits in a passive avoidance test with less motor deficits than other surgical models [53]. However, this model does not resolve the main weakness of the MCA model, since the induced cerebral embolism lacks common causation with MID [49]. The locations of the infarcts induced by the ischemia are also difficult to reproduce between animals [49].

The SHRSP model was developed in the 1960s, but it was not applied to the study of VaD until the 1990s. These rats were created by inbreeding Wistar-Kyoto rats for a hypertensive phenotype with a significant percentage developing blood pressure greater than $200 \mathrm{~mm} \mathrm{Hg}$ [54]. When these rats begin to experience multiple strokes, the locations of these events more closely recapitulate the typical sites of strokes in humans than do the other experimental models, with branching arteries in watershed areas being highly affected [55]. These animals also have cognitive deficits, displaying impairment on passive avoidance tests [49]. Hence, the SHRSP model was advanced as a promising tool for studying MID pathophysiology as well as acute stroke based on its high construct validity [49].

\section{Diagnostic Criteria}

As the focus on vascular contributions to dementia began to reemerge in research and clinical trials, reliable criteria for identifying and distinguishing VaD were needed. Soon after describing MID, Hachinski et al. [56] developed an 18-point ischemic score which successfully separated primary senile dementia from MID. However, despite its accepted sensitivity for detecting dementia linked to vascular disruptions, concerns about the specificity of the Hachinski ischemic score led to the development of other clinical diagnostic criteria in the 1990s. Thus, the Alzheimer's Disease Diagnostic and Treatment Centers (ADDTC) criteria and the National Institute of Neurological Disorders and Stroke-Association Internationale pour la Recherche et l'Enseignement en Neurosciences (NINDS-AIREN) criteria were developed in this decade $[57,58]$.

The ADDTC criteria, published in 1992, were established in response to the difficulty in identifying mixed dementia cases and differentiating VaD subtypes with the Hachinski ischemic scale [57]. The ADDTC criteria introduced the diagnostic categories of possible and probable VaD as well as of mixed dementia, with the instruction that CT and MRI evaluation of infarcts and white matter rarefication be included along with a functional neurological evaluation [57]. Today, the ADDTC criteria are considered among the most specific criteria for the diagnosis of $\mathrm{VaD}$, but their lack of sensitivity compared to the Hachinski ischemic scale has also been noted [59].

The NINDS-AIREN criteria were published the following year, noting that the previous criteria placed the emphasis only on ischemic causes of $\mathrm{VaD}$ while ignoring the heterogeneity of cerebrovascular disease (CVD) contributing to the onset of dementia [58]. The NINDSAIREN criteria suggested 3 broad requirements for the diagnosis of probable VaD: (1) the presence of dementia, (2) the presence of CVD, which had to include CT or MRI data, and (3) an indication for a causal role of the CVD in dementia, by its presence prior to the emergence of dementia [58]. The NINDS-AIREN criteria are the most commonly used criteria for the diagnosis of VaD today, though the same concerns that plague the ADDTC criteria - a lack of sensitivity - are also noted for the NINDS-AIREN criteria [59].

Recent advances in carefully defining and delineating VaD for the purposes of research and clinical trials have been the focus of both the National Institute of Neurological Disorders and Stroke and Canadian Stroke Network harmonization workshop and the American Heart Association and American Stroke Association writing group for vascular cognitive impairment (VCI) $[3,60]$. This broader term, "vascular cognitive impairment," has resulted from the 
recent acknowledgment that some mild cognitive impairment cases are the result of vascular dysfunction. Recommendations from these 2 groups included minimal neuropsychiatric and neuroimaging evaluations for the diagnosis of VCI [60], and encouragement of the consideration of risk factors that may be either convergent or divergent in the etiology of VCI or $\mathrm{AD}[3]$.

\section{The 2000s to the Present: Mechanisms and a Return to Treatment}

\section{Inflammation}

At the turn of this century, the role of inflammation in disease became a prominent area of interest for understanding dementias, including $\operatorname{VaD}$ and $\mathrm{AD}[61,62]$. An initial focus of these studies was to determine whether increased levels of proinflammatory proteins in cerebrospinal fluid from dementia patients were related to neuronal death, and whether these factors were antecedent causative agents or risk factors for clinical onset [61-63]. In this regard, several longitudinal aging studies found that elevated levels of certain proinflammatory cytokines preceded the onset of dementia, suggesting a potential pathogenic role for neurovascular inflammatory pathways in the clinical presentation of the disease [61-63]. For $\mathrm{VaD}$ in particular, elevations of $\alpha_{1}$-antichymotrypsin and C-reactive protein plasma levels were predictive of premorbid risk $[61,62]$. An imbalance in pro- and anti-inflammatory cytokines was especially pronounced in MID patients compared to controls and subjects with other dementias, with an increase in TNF and a deficit in IL-10 production providing further evidence of an aberrant proinflammatory state [63].

Genetic studies also revealed potential variations in proinflammatory cytokines between VaD patients and cognitively normal controls $[64,65]$. In a study of over 100 MID patients and aged-matched controls, Pola et al. [64] found that the G allele of the $-174 \mathrm{G} / \mathrm{C}$ polymorphism in the IL-6 gene was 9 times more likely to occur in the MID group. McCusker et al. [65] found a significantly higher occurrence of the T allele in the TNF C/T polymorphism in VaD patients compared to stroke patients without dementia. These results suggested that a genetic risk for VaD could be conveyed through polymorphisms in the regulatory regions of proinflammatory cytokines.

Furthermore, the possibility of a causal role of inflammation in ischemic stroke emerged with an increased understanding of the pathways leading to thromboembolisms [66, 67]. In this regard, vascular endothelial cells are activated by inflammatory mediators under injurious conditions and express adhesion molecules that encourage immune cells to deposit in the subendothelial wall of the vessels [66]. Some of these immune cells then release cytokines that trigger the release of matrix metalloproteases from other immune cells which degrade parts of the plaque, leading to rupture or embolism [67]. The discovery of this pathway resulted in an expanded understanding of the role of inflammation in strokes leading to dementia, rather than simply being a response to the damage done.

More recently, an increased focus on the role of the endothelium in VaD has led to an increased awareness of small vessel disease in certain subcortical VaD subtypes [68]. As opposed to the long-accepted role of thromboembolism in VaD proposed by C.M. Fisher, the incidence of white matter damage is now believed to result from arteriole disease, while thromboembolism is linked to cortical damage [68]. Inflammation, hypertension, and oxidative stress have been suggested to induce endothelial dysfunction as an early instigator of local vessel occlusions [69]. 


\section{Sex Differences}

The preexisting NIH Revitalization Act of 1993 required women to be included in any clinical research receiving NIH funding, which led to an enhancement of studies on sex differences in many disorders. Furthermore, the realization that translational research which was focused entirely on male preclinical animal models could result in unpredicted deleterious drug reactions in women in clinical trials [70] led the NIH to enact new guidelines for 2014 in which grant applicants must balance male and female animals and/or primary cells in all studies unless a valid reason exists not to do so [71]. These efforts to focus on potential sex differences in disease has resulted in conflicting results on the contribution of gender in susceptibility to MID [72-74].

As discussed, some researchers in the 1980s reported a greater proportion of males than females experiencing MID [30], suggesting a differential vulnerability to risk factors for the disease. For instance, some meta-analyses concluded that in the early years of risk, as a person enters their 60s, more males than females develop dementia after suffering a stroke, but that this difference disappears when looking at older samples of individuals with $\mathrm{VaD}$ [74]. Interestingly, this mimics the incidence rates of stroke among males and females observed in longitudinal studies, with men suffering more strokes than women until the age of 85 years, when women surpass men in rates of stroke [75]. This suggests that sex differences in rates of stroke, rather than rates of dementia as an outcome of stroke, might be to blame for this increased risk for MID observed in men. On the other hand, Pendlebury and Rothwell [73] found a higher rate of females with dementia following stroke in a mix of hospital-and population-based samples of patients. However, they noted that the higher rate of dementia following stroke in females was often accounted for by dementia that had been present before the stroke [73]. As the occurrence of AD already has an established sex difference, affecting women more than men [76], this observation could easily be the result of more females than males having preexisting dementia symptoms unrelated to stroke.

Finally, some studies have reported a significant difference in rates of $\mathrm{VaD}$ with age and race, but not with sex [72]. When Kuller et al. [72] examined over 3,300 participants without any clinical dementia over nearly 6 years, they arrived at similar conclusions to those suggested by research in the 1980s, namely, that physiological risk factors such as hypertension, diabetes, and a history of cerebral vascular disease were the greatest predictors of $\mathrm{VaD}$. When these results were controlled for age and race, the sex differences disappeared for $\mathrm{VaD}$ and mixed dementias, but not for AD [72]. Therefore, the field is currently split over whether a sex difference exists for MID, but highly controlled studies have failed to find a significant difference.

\section{Renewed Hope for Treatment}

Despite the disappointments with MID treatments in prior decades, the new century brought renewed hope for efficacious pharmacological interventions [7, 77]. Though no treatment has yet moved beyond clinical trials to meet regulatory approval, the research community's improved understanding of the disease raises the prospect of finding a viable intervention [7]. A few of the drugs that initially seemed the most promising included acetylcholinesterase inhibitors and the antihypertensive calcium channel blocker nimodipine $[78,79]$.

Several acetylcholinesterase inhibitors are approved for the symptomatic management of moderate AD [80]. Among these, galantamine and donepezil showed only mild improvements in executive function, no improvement in any other clinical measures, and some deleterious side effects in early MID clinical trials [78].

Nimodipine was the subject of several therapeutic trials of MID at the start of the 21st century by Pantoni et al. [79, 81]. As nimodipine has a vasodilatory effect on small vessels, 
it was thought that it would be helpful in maintaining perfusion in areas most sensitive to ischemic events [79]. These patients showed improvement versus controls in measures of neuropsychological and executive function but not motor functions [79]. Subsequently, it was discovered that these improvements were limited to the subgroup with subcortical lesions only [79]. However, nimodipine has since seen little attention in further clinical trials [7].

Current clinical trials for the treatment of $\mathrm{VaD}$ with forthcoming results include rivastigmine (NCT00130338) and cilostazol (NCT00847860). Rivastigmine is another acetylcholinesterase inhibitor with some cognitive benefits in previous clinical trials of $\mathrm{VaD}$ when AD was also a probable contributor to cognitive dysfunction [82]. Cilostazol has been suggested as a VaD treatment when diabetes is a significant contributing risk factor based on improved Morris water maze performance in rat models of diabetes [83].

\section{Conclusion}

This historical perspective offers clarity and anticipation regarding what new milestones might await in the coming decades. Looking back at the progress of MID research from the start of the 1970s provides a sense of just how far the field has come in a handful of decades. The 1970s marked a period of reliance on human autopsy and clinical data that allowed for the differentiation of MID from the primary dementias in both clinical presentation and pathological hallmarks. In the 1980s, the study of MID pathophysiology experienced a decline, with management of risk factors and the suggestion of diagnostic amendments comprising the bulk of the focus of the limited research studies. The 1990s witnessed a resurgence of the scientific community's interest in MID, and $\mathrm{VaD}$ in general, as new technologies and animal models allowed for thorough and specific inspection of its progression and etiology in inducible models and with a mechanistic focus. Since the beginning of the 21st century, MID and the VaDs have been increasingly recognized as a health issue commanding attention with regard to finding unique and specific mechanisms and treatments, in addition to the potential role for vascular contributions to mixed dementia and AD. This recent revival in interest and reintegration of vascular considerations in neurologic disease etiology will hopefully result in new disease-modifying therapeutic strategies in order to augment preventative efforts to reduce risk factors for the cerebrovascular insults underlying these dementing disorders.

\section{Acknowledgements}

This study was supported by grants AG014449, AG042146, and AG053760 from the National Institute on Aging, National Institutes of Health; by the Saint Mary's Foundation; and by Miles for Memories of Battle Creek, MI.

\section{Disclosure Statement}

The authors report no conflicts of interest. 


\section{References}

1 Thal DR, Grinberg LT, Attems J: Vascular dementia: different forms of vessel disorders contribute to the development of dementia in the elderly brain. Exp Gerontol 2012;47:816-824.

12 Iadecola C: The pathobiology of vascular dementia. Neuron 2013;80:844-866.

3 Gorelick PB, Scuteri A, Black SE, Decarli C, Greenberg SM, Iadecola C, et al: Vascular contributions to cognitive impairment and dementia: a statement for healthcare professionals from the American Heart Association/ American Stroke Association. Stroke 2011;42:2672-2713.

-4 Jellinger KA: Pathology and pathogenesis of vascular cognitive impairment - a critical update. Front Aging Neurosci 2013;5:17.

5 Román G: Vascular dementia: distinguishing characteristics, treatment and prevention. J Am Geriatr Soc 2003;51(suppl dementia):S296-S304.

6 Hill J, Fillit H, Shah S, del Valle MC, Futterman R: Patterns of healthcare utilization and costs for vascular dementia in a community-dwelling population. J Alzheimers Dis 2005;8:43-50.

7 Baskys A, Cheng JX: Pharmacological prevention and treatment of vascular dementia: approaches and perspectives. Exp Gerontol 2012;47:887-891.

8 Jorm AF, Jolley D: The incidence of dementia: a meta-analysis. Neurology 1998;51:728-733.

-9 Ferri CP, Prince M, Brayne C, Brodaty H, Fratiglioni L, Ganguli M, et al; Alzheimer's Disease International: Global prevalence of dementia: a Delphi consensus study. Lancet 2005;366:2112-2117.

10 Greenlund KJ, Croft JB, Mensah GA: Prevalence of heart disease and stroke risk factors in persons with prehypertension in the United States, 1999-2000. Arch Intern Med 2004;164:2113-2118.

$>11$ O’Brien JT, Thomas A: Vascular dementia. Lancet 2015;386:1698-1706.

12 Scholz W: Studien zur Pathologie der Hirngefässe II. Die drusige Entartung der Hirnarterien und Capillaren. Z Ges Neurol Psychiatrie 1938;162:694-715.

$\checkmark 13$ Alzheimer A: Neuere Arbeiten über die Dementia senilis und die auf atheromatöser Gefässerkrankung basierenden Gehirnkrankheiten. Eur Neurol 1898;3:101-115.

14 Alzheimer A: About a peculiar disease of the cerebral cortex. Allg Z Psychiatrie Psych Gerichtl Med 1907;64: 146-148.

15 Hachinski V, Lassen N, Marshall J: Multi-infarct dementia: a cause of mental deterioration in the elderly. Lancet 1974;304:207-209.

16 Corsellis JA, Evans PH: The relation of stenosis of the extracranial cerebral arteries to mental disorder and cerebral degeneration in old age; in Proc 5th Int Congr Neuropathol. Amsterdam, Excerpta Medica, 1965, pp 546-548.

17 Worm-Petersen J, Pakkenberg H: Atherosclerosis of cerebral arteries, pathological and clinical correlations. J Gerontol 1968;23:445-449.

18 Fisher CM: Dementia in cerebral vascular disease; in Toole JF, Siekert RG, Wisnunt JP (eds): Transactions of the Sixth Congress on Cerebral Vascular Diseases. New York, Grune \& Stratton, 1968, pp 232-236.

19 Blackwood W, Hallpike JF, Kocen RS, Mair WG: Atheromatous disease of the carotid arterial system and embolism from the heart in cerebral infarction: a morbid anatomical study. Brain 1969;92:897-910.

20 Karp H: Dementia in adults; in Baker A, Baker L (eds): Clinical Neurology. Hagerstown, Harper \& Row, 1973, chapter 27.

21 Perez FI, Rivera VM, Meyer JS, Gay JR, Taylor RL, Mathew NT: Analysis of intellectual and cognitive performance in patients with multi-infarct dementia, vertebrobasilar insufficiency with dementia, and Alzheimer's disease. J Neurol Neurosurg Psychiatry 1975;38:533-540.

22 Birkett DP: The psychiatric differentiation of senility and arteriosclerosis. Br J Psychiatry 1972;120:321-325.

23 Marsden CD, Harrison MJ: Outcome of investigation of patients with presenile dementia. Br Med J 1972;2: 249-252.

24 Tomlinson BE, Blessed G, Roth M: Observations on the brains of demented old people. J Neurol Sci 1970;11: 205-242.

25 Szanto S: Blood platelet behaviour in primary neuronal and vascular dementia. Age Ageing 1972;1:207-212.

-26 Yesavage JA, Tinklenberg JR, Hollister LE, Berger PA: Vasodilators in senile dementias: a review of the literature. Arch Gen Psychiatry 1979;36:220-223.

-27 Walsh AC: Anticoagulant therapy as a potentially effective method for the prevention of presenile dementia: two case reports. J Am Geriatr Soc 1968;16:472-481.

28 Coon WW, Willis PW 3rd: Hemorrhagic complications of anticoagulant therapy. Arch Intern Med 1974;133: 386-392.

29 Whisnant JP, Cartlidge NE, Elveback LR: Carotid and vertebral-basilar transient ischemic attacks: effect of anticoagulants, hypertension, and cardiac disorders on survival and stroke occurrence - a population study. Ann Neurol 1978;3:107-115.

30 Meyer JS, McClintic KL, Rogers RL, Sims P, Mortel KF: Aetiological considerations and risk factors for multiinfarct dementia. J Neurol Neurosurg Psychiatry 1988;51:1489-1497.

-31 Meyer JS, Judd BW, Tawaklna T, Rogers RL, Mortel KF: Improved cognition after control of risk factors for multi-infarct dementia. JAMA 1986;256:2203-2209.

-32 Katzman R: Dementias. Postgrad Med 1978;64:119-125. 
Roth M: Classification and aetiology in mental disorders of old age: some recent developments; in Kay DWK, Walk A (eds): Recent Developments in Psychogeriatrics. Ashford, Headley Brothers, 1971, pp 1-10.

-34 Ishii N, Nishihara Y, Imamura T: Why do frontal lobe symptoms predominate in vascular dementia with lacunes? Neurology 1986;36:340-345.

35 Hachinski VC: The decline and resurgence of vascular dementia. CMAJ 1990;142:107-111.

36 Binswanger O: Die Abgrenzung der allgemeinen progressiven Paralyse. Berl Klin Wochenschr 1894;31:1103$1105,1137-1139,1180-1186$

-37 George AE, de Leon MJ, Gentes CI, Miller J, London E, Budzilovich GN, et al: Leukoencephalopathy in normal and pathologic aging: 1. CT of brain lucencies. AJNR Am J Neuroradiol 1986;7:561-566.

38 De Reuck J, Crevits L, De Coster W, Sieben G, vander Eecken H: Pathogenesis of Binswanger chronic progressive subcortical encephalopathy. Neurology 1980;30:920-928.

39 De Reuck J: The human periventricular arterial blood supply and the anatomy of cerebral infarctions. Eur Neurol 1971;5:321-334.

40 Goldman SA, Pulsinelli WA, Clarke WY, Kraig RP, Plum F: The effects of extracellular acidosis on neurons and glia in vitro. J Cereb Blood Flow Metab 1989;9:471-477.

-41 Erkinjuntti T, Ketonen L, Sulkava R, Sipponen J, Vuorialho M, Iivanainen M: Do white matter changes on MRI and CT differentiate vascular dementia from Alzheimer's disease? J Neurol Neurosurg Psychiatry 1987;50: $37-42$.

-42 Roberts MA, McGeorge AP, Caird FI: Electroencephalography and computerised tomography in vascular and non-vascular dementia in old age. J Neurol Neurosurg Psychiatry 1978;41:903-906.

43 Radue EW, du Boulay GH, Harrison MJ, Thomas DJ: Comparison of angiographic and CT findings between patients with multi-infarct dementia and those with dementia due to primary neuronal degeneration. Neuroradiology 1978;16:113-115.

44 Brant-Zawadzki M, Fein G, Van Dyke C, Kiernan R, Davenport L, de Groot J: MR imaging of the aging brain: patchy white-matter lesions and dementia. AJNR Am J Neuroradiol 1985;6:675-682.

45 Heiss WD, Rosenberg GA, Thiel A, Berlot R, de Reuck J: Neuroimaging in vascular cognitive impairment: a state-of-the-art review. BMC Med 2016;14:174.

46 Chabriat H, Vahedi K, Bousser MG, Iba-Zizen MT, Joutel A, Nibbio A, et al: Clinical spectrum of CADASIL: a study of 7 families. Cerebral autosomal dominant arteriopathy with subcortical infarcts and leukoencephalopathy. Lancet 1995;346:934-939.

47 Joutel A, Corpechot C, Ducros A, Vahedi K, Chabriat H, Mouton P, et al: Notch3 mutations in CADASIL, a hereditary adult-onset condition causing stroke and dementia. Nature 1996;383:707-710.

48 Ruchoux MM, Maurage CA: CADASIL: cerebral autosomal dominant arteriopathy with subcortical infarcts and leukoencephalopathy. J Neuropathol Exp Neurol 1997;56:947-964.

49 Saito H, Togashi H, Yoshioka M, Nakamura N, Minami M, Parvez H: Animal models of vascular dementia with emphasis on stroke-prone spontaneously hypertensive rats. Clin Exp Pharmacol Physiol Suppl 1995;22:S257S259.

-50 Tamura A, Graham DI, McCulloch J, Teasdale GM: Focal cerebral ischaemia in the rat: 1. Description of technique and early neuropathological consequences following middle cerebral artery occlusion. J Cereb Blood Flow Metab 1981;1:53-60.

51 Garcia JH, Yoshida Y, Chen H, Li Y, Zhang ZG, Lian J, et al: Progression from ischemic injury to infarct following middle cerebral artery occlusion in the rat. Am J Pathol 1993;142:623-635.

52 Miyake K, Takeo S, Kaijihara H: Sustained decrease in brain regional blood flow after microsphere embolism in rats. Stroke 1993;24:415-420.

53 Tagaki N, Miyake K, Taguchi T, Sugita N, Tagaki K, Tamada H, et al: Changes in cholinergic neurons and failure in learning function after microsphere embolism-induced cerebral ischemia. Brain Res Bull 1997;43:87-92.

54 Okamoto K, Aoki K: Development of a strain of spontaneously hypertensive rats. Jpn Circ J 1963;27:282-293.

55 Yamori Y, Horie R, Handa H, Sato M, Fukase M: Pathogenetic similarity of strokes in stroke-prone spontaneously hypertensive rats and humans. Stroke 1976;7:46-53.

56 Hachinski VC, Iliff LD, Zilhka E, Du Boulay GH, McAllister VL, Marshall J, et al: Cerebral blood flow in dementia. Arch Neurol 1975;32:632-637.

57 Chui HC, Victoroff JI, Margolin D, Jagust W, Shankle R, Katzman R: Criteria for the diagnosis of ischemic vascular dementia proposed by the State of California Alzheimer's Disease Diagnostic and Treatment Centers. Neurology 1992;42(pt 1):473-480.

-58 Román GC, Tatemichi TK, Erkinjuntti T, Cummings JL, Masdeu JC, Garcia JH, et al: Vascular dementia: diagnostic criteria for research studies. Report of the NINDS-AIREN International Workshop. Neurology 1993;43: 250-260.

59 Kalaria RN: Neuropathological diagnosis of vascular cognitive impairment and vascular dementia with implications for Alzheimer's disease. Acta Neuropathol 2016;131:659-685.

60 Hachinski V, Iadecola C, Petersen RC, Breteler MM, Nyenhuis DL, Black SE, et al: National Institute of Neurological Disorders and Stroke-Canadian Stroke Network vascular cognitive impairment harmonization standards. Stroke 2006;37:2220-2241.

61 Engelhart MJ, Geerlings MI, Meijer J, Kiliaan A, Ruitenberg A, van Swieten JC, et al: Inflammatory proteins in plasma and the risk of dementia: the Rotterdam Study. Arch Neurol 2004;61:668-672. 
62 Schmidt R, Schmidt H, Curb JD, Masaki K, White LR, Launer LJ: Early inflammation and dementia: a 25-year follow-up of the Honolulu-Asia Aging Study. Ann Neurol 2002;52:168-174.

63 De Luigi A, Fragiacomo C, Lucca U, Quadri P, Tettamanti M, Grazia De Simoni M: Inflammatory markers in Alzheimer's disease and multi-infarct dementia. Mech Ageing Dev 2001;122:1985-1995.

64 Pola R, Gaetani E, Flex A, Aloi F, Papaleo P, Gerardino L, et al: -174 G/C interleukin-6 gene polymorphism and increased risk of multi-infarct dementia: a case-control study. Exp Gerontol 2002;37:949-955.

65 McCusker SM, Curran MD, Dynan KB, McCullagh CD, Urquhart DD, Middleton D, et al: Association between polymorphism in regulatory region of gene encoding tumour necrosis factor $\alpha$ and risk of Alzheimer's disease and vascular dementia: a case-control study. Lancet 2001;357:436-439.

66 Lindsberg PJ, Grau AJ: Inflammation and infections as risk factors for ischemic stroke. Stroke 2003;34:25182532.

67 McColl BW, Allan SM, Rothwell NJ: Systemic infection, inflammation and acute ischemic stroke. Neuroscience 2009;158:1049-1061.

68 Wardlaw JM, Smith C, Dichgans M: Mechanisms of sporadic cerebral small vessel disease: insights from neuroimaging. Lancet Neurol 2013;12:483-497.

69 Mudau M, Genis A, Lochner A, Strijdom H: Endothelial dysfunction: the early predictor of atherosclerosis. Cardiovasc J Afr 2012;23:222-231.

70 Franconi F, Brunelleschi S, Steardo L, Cuomo V: Gender differences in drug responses. Pharmacol Res 2007;55: 81-95.

71 Clayton JA, Collins FS: Policy: NIH to balance sex in cell and animal studies. Nature 2014;509:282-283.

72 Kuller LH, Lopez OL, Jagust WJ, Becker JT, DeKosky ST, Lyketsos C, et al: Determinants of vascular dementia in the Cardiovascular Health Cognition Study. Neurology 2005;64:1548-1552.

73 Pendlebury ST, Rothwell PM: Prevalence, incidence, and factors associated with pre-stroke and post-stroke dementia: a systematic review and meta-analysis. Lancet Neurol 2009;8:1006-1018.

74 O’Brien JT: Vascular cognitive impairment. Am J Geriatr Psychiatry 2006;14:724-733.

75 Petrea RE, Beiser AS, Seshadri S, Kelly-Hayes M, Kase CS, Wolf PA: Gender differences in stroke incidence and poststroke disability in the Framingham Heart Study. Stroke 2009;40:1032-1037.

76 Jorm AF, Korten AE, Henderson AS: The prevalence of dementia: a quantitative integration of the literature. Acta Psychiatr Scand 1987;76:465-479.

77 Pantoni L: Treatment of vascular dementia: evidence from trials with non-cholinergic drugs. J Neurol Sci 2004;226:67-70.

-78 Kavirajan H, Schneider LS: Efficacy and adverse effects of cholinesterase inhibitors and memantine in vascular dementia: a meta-analysis of randomised controlled trials. Lancet Neurol 2007;6:782-792.

79 Pantoni L, Rossi R, Inzitari D, Bianchi C, Beneke M, Erkinjuntti T, et al: Efficacy and safety of nimodipine in subcortical vascular dementia: a subgroup analysis of the Scandinavian Multi-Infarct Dementia Trial. J Neurol Sci 2000;175:124-134.

80 Raschetti R, Maggini M, Sorrentino GC, Martini N, Caffari B, Vanacore N: A cohort study of effectiveness of acetylcholinesterase inhibitors in Alzheimer's disease. Eur J Clin Pharmacol 2005;61:361-368.

-81 Pantoni L, Carosi M, Amigoni S, Mascalchi M, Inzitari D: A preliminary open trial with nimodipine in patients with cognitive impairment and leukoaraiosis. Clin Neuropharmacol 1996;19:497-506.

82 Ballard C, Sauter M, Scheltens P, He Y, Barkhof F, van Straaten EC, et al: Efficacy, safety and tolerability of rivastigmine capsules in patients with probable vascular dementia: the VantagE study. Curr Med Res Opin 2008;24:2561-2574.

83 Kumar A, Kumar A, Jaggi AS, Singh N: Efficacy of cilostazol a selective phosphodiesterase-3 inhibitor in rat model of streptozotocin diabetes induced vascular dementia. Pharmacol Biochem Behav 2015;135:20-30. 